\title{
REFRAMING TRANSLATIONAL RESEARCH AS TRANSACTIONAL RESEARCH:
}

\author{
An analysis of clinician-scientists' work practices \\ in a Danish hospital setting
}

by Dixi Louise Strand

Translational research (TR) is subject to increasing attention and demand in research and health policy in the Nordic countries as well as internationally. While clinician-scientists are often positioned as key actors in both policy and academic debates on TR, less is known about the clinician-scientists' everyday work-their practices and commitments at the interface of academia and clinical health care. Drawing on the framework of arena analysis, developed in situational analysis, this article presents an empirical exploration of the everyday practices of clinician-scientists by extending research into a Danish hospital setting. The findings shed light on hospital-based translational research as constituted by clinician-scientists' practical integration of and transactions across many different work practice arenas. This paper depicts these arenas and the complex of commitments and capabilities involved. The analysis converges with existing Science and Technology Studies approaches to translational research as mutually reconfiguring clinical and scientific practices. In addition, it adds to this debate by providing an empirical work practice account of hospital-based TR and by suggesting a conceptual reframing of translational research as transactional research. 


\section{Introduction}

"Translation" of scientific research into clinical care and measurable health outcomes are desirable in health policy debates as a way of ensuring that public investments in health science are paid back in the form of improved care practice and improved public health. Policy documents and studies in this area have pointed to the crucial mediating role of clinician-scientists as hybrid professionals with expertise in both clinical practice and scientific research (Michael et al., 2007; Wainwright and Williams, 2009; Wilson-Kovacs and Hauskeller, 2012). By virtue of this dual role, having a foot in both worlds, they potentially facilitate the paths and adaptations of knowledge across what is often perceived as disparate institutional logics or translational gaps between research and clinic.

This paper explores how individuals employed as clinician-scientists and engaged in translational research (TR) carry out the day-to-day hospital-based research work in a Danish setting. Methodologically, the study draws on theory and methods from the field of organizational ethnography and Science and Technology Studies (STS) (Clarke, 2005; Law, 2017). As the empirical study and analytical mapping evolved over a one-year period, a key characteristic of clinician-scientists' TR work was the ability to bring together multiple capacities, match the skills needed and continuously meet the differing and divergent demands and performance requirements.

The paper therefore seeks to shares this complex of work practices, using the concept of arenas from situational analysis (Clarke, 2005; 125). The analysis sheds light on the organizational and technical complexity involved in TR as well as the scope of the specialized knowledges involved. As such, the analysis converges with other STS studies in this area and adds to this debate by providing an empirical work practice account of hospital-based TR. Subsequently, a reframing of TR as transactional research is proposed as a conceptualization that points to the highly complex and multiple practices of clinician-scientists through which connections and transactions between research and clinic can emerge.

The paper is structured as follows. The first part provides a brief review of how research translation is depicted in the normative policy-related TR debate and within the field of STS. The second part introduces the setting for the empirical case studies, the methodological framework of the study and the theoretical underpinning for the empirical study and analysis. Then an analysis of the arenas is presented followed by a discussion and conclusion.

\section{Translational research}

The term "translational research" (also referred to as translational medicine, translational science, and academic medicine) was first used in a US national cancer program in the 9o's and has since become a very popular concept in medical and health research (Fudge et al., 2016; Woolf, 2008). The concept appears in research programs, research strategies, academic articles and journals, policy reports, educational programs etc. and is the subject of much debate in the fields of medicine, nursing and public health studies. The main interest underlying the concept in this normative policy oriented debate derives from a perceived series of gaps between life sciences, medical research, clinical practices, and effects in the form of e.g. measurable health improvements. Literature reviews of the TR debate reveal a wide range of ways in which the concept is used (Greenhalgh and Wieringa, 2011; van der Laan and Boenink, 2015). Yet, an overarching trope of bench and bedside recurs in the health literature and policy; that of research and clinic as two different worlds or logics (Dunn and Jones, 2010). Here the logics of care are often characterized by clinical experience, diagnostic testing and other "arts" of medicine (Malterud, 2001), whereas science logics grow out of a different and separate researcher profession and a different set of academic norms (Miller and French, 2016).

\section{Science and Technology Studies}

In the field of Science and Technology Studies, interactions of "bench and bedside" have also been the object of interest and study. Seminal historical science studies in this area include Knorr-Certina on epistemic cultures (Knorr-Cetina, 1999), Löwy's historical bench-to bedside study of immunology's path into the cancer clinic (Löwy, 1996), Fujimura's study of networks between basic researchers, clinical practitioners, and funding agencies and their coordinated "crafting" of new genetic approaches to particular forms of cancer (Fujimura, 1996), and Mol's study on the multiple nature of arthrosclerosis (Mol, 2002). Noteworthy studies in this field have also analyzed how the "adoption" of scientific results is dependent upon the building and extension of social and technical networks (Latour 1987; Timmermans \& Berg, 2003). More recent research has focussed on the socio-technical, regulatory and ethical practices of working across research and clinic (e.g. Moreira, May, and Bond 2009; Michael, Wainwright, and Williams 2007) and has established a new understanding of scientific research and clinical work as performed and intersecting within biomedical collectives (Bourret, 2005; Keating and Cambrosio, 2012). This work has served to disrupt the notion of research and clinic as two separate domains and to shift focus to how these very categories are contingent and relational.

Research within STS has pointed to the crucial positioning of clinician-scientists as key professionals with expertise in both clinical practice and scientific research. The notion of boundaries and boundary work is a prevalent theme in the existing studies, e.g. positioning the clinician-scientist as a boundary spanner or broker across boundaries of clinic and science (Löwy, 1996; Swan et.al. 2007; Wilson-Kovacs and Hauskeller, 2012; Lander, 2016a, 2016b; Miller and French, 2016). Another notable analytical theme within this line of empirical studies is the notion of hybridity, the clinicianscientist as a "hybrid professional" (Brosnan et al., 2013; Brosnan and Michael, 2014; Wainwright and Williams, 2009) or "user-producer 


\section{N}

NORDIC JOURNAL

of Science and Technology Studies

hybrid" (Douglas et al., 2015; Dunn and Jones, 2010; Hendriks et al., 2019). These studies of boundary work and hybridization call for new analytical conceptualizations that cut across assumed divides of knowledge users and producers - and separate worlds of clinic and research. They also point to a professional field of practice in the making and in reconfiguration. The study presented converges with and adds to this body of literature by providing an empirical account that views these boundary practices and hybridity through the analytical lens of situational analysis and employing an empirically grounded practice approach. Crabu offers a thorough meta-analysis of sociological research examining translational medicine and finds that empirical work has mainly focussed on laboratories and crossovers between the laboratory and the clinic (Crabu, 2018). The paper thus also adds to empirical hospital-based studies of translational research, since few STS studies take hospital-based clinician-scientists as the starting point for examining translational medicine (Rabeharisoa and Bourret, 2009).

\section{Theory}

Situational analysis is based on Haraway's understanding of situated knowledge (Haraway, 1988), Michel Foucault's discourse analysis (Foucault, 1990), and Anselm Strauss' social world/arena theory (Strauss, 1993) and is an important methodological and theoretical contribution to the interdisciplinary STS research tradition. Situational analysis rests upon a theoretical understanding of knowledge as always embedded and enacted in the situations of which it is a part (Clarke, 2005). In this understanding, knowledge is always incorporated in practices, procedures, techniques and technologies. The focus here is therefore specifically on practice, on what clinician-scientists do and how they do it. In situational analysis, contextual and macro elements are understood as actually present in practice, or the analytically delineated "situation". Context, or macro, is thus not mapped as being outside, something exterior to a situation, but as part of and constitutive of practice. This approach has as a main unit of analysis the relations among actors including non-human actors. In Clarke's terms situational analysis is not a grand sociological theory, but rather a "theory/method package" in which a series of analytical tools and sensitizing concepts are put forward to be adjusted and refined in relation to the particular study (Clarke, 2005; 125). I apply "arena analysis", one tool in situational analysis, as a form of complexity mapping of the way in which commitments and capabilities were organized around the clinician-scientists. What are the patterns of collective commitment? How do the clinician-scientists go about fulfilling these commitments? Arenas are characterized by Clarke as multiple, complex and layered discursive and material constructions, groups of actors (human and non-human), knowledges, and practices that persist over time (Clarke, 2005; 125). They are sets of practices (committed to and bounded by collective action/work of some kind) and not necessarily formal organizations.

\section{Setting}

The setting for the research here is Region Zealand in Denmark and in particular two research networks based in the hospitals in the region. These research networks connect different research projects or research protocols within a joint vision of changing and improving diagnosis and/or treatment within a given area. The two research networks lie within two very different medical areas, child and youth psychiatric diagnosis and cancer treatment. I selected these two research networks based on a completed research evaluation of all departments in 2017 in which research and translational activities have been mapped (Region Zealand Operations Research and Innovation, 2017). The networks are exemplary in that one network is at an early career start-up phase based in a department with sparse prior research, and the other comprises more established researchers in departments where research capacity was stronger and expanding. In this way, the two cases illustrate a breath across two different medical specialties and "stages of research maturity" at a department.

The cancer treatment research network aimed to develop electroporation treatment for cancer, a technique that applies an electrical field to cells in order to increase the permeability of the cell membrane, allowing chemicals, drugs, or DNA to be introduced into the cell. A range of related projects sought to refine the technique in relation to specific cancer types, and in relation to different types of chemicals, as well as to explore systemic immune responses found clinically as an unexpected outcome of the treatment. The psychiatric research network studied examined autism disorders in children and youth through a "translational" research design combining clinical and biological methods, questioning and potentially informing the very disorder category, current diagnostic criteria and classification. Although several of the projects within both of these research networks included industrial partners, the initiators themselves stressed that the research was "investigatorinitiated" and thus different in nature from clinical trials and medical research driven by industry, another type of research also on the rise at the hospitals in question. The lead researchers themselves defined the research as "translational research".

A politically driven effort to expand and utilize research activity at the hospitals was relatively new in this region compared to some 


\section{N}

NORDIC JOURNAL

of Science and Technology Studies

of the other regions in Denmark. In fall 2013, a centralized research support unit was established in Region Zealand along with plans for an increase in the hospitals' research budget. Funding for research projects, research infrastructure, and clinical-scientist research positions, shared between a hospital and a university, have since grown expansively. In March 2016, two hospitals were merged and entered into a stronger collaboration and formed a new joint organizational structure with a university.
These initiatives mark the increased organizational commitment towards research and education as an integral part of a clinical care agenda. At the end of 2018, the region had approximately sixty employees holding the formal position of clinician-scientist, having a part-time academic employment alongside a clinical position, and strategic plans were underway to greatly increase this number in the coming years - as well as to involve and engage additional clinical staff in research.

\section{Methods}

Data collection was conducted between January 2018 and March 2019 and comprised interviews, observations, and collecting of organizational and project documents. Observations included research team meetings, departmental meetings, public presentations of research, two academic conferences, patient testing and treatment, and lab visits, and informal conversations (approx. 100 hours). A guiding focus of the observations was an exploratory research question: what characterizes translational activities and situations in the hospital-based research networks. Observations and informal conversations provided data on daily experiences and were linked to formal interviews that were conducted in parallel. 20 in-depth interviews were conducted with primarily clinicianscientists (n11) as well as research team members such as Ph.D. students (n4), biologists (n2), an engineer (n1), and department managers (n2). The interviews lasted 1-2 hours, were recorded and transcribed with the respondent's consent. All interviews were conducted at the hospitals and were semi-structured around questions about professional background, research activities, and in particular the selected focus project. The interviews also included questions about the participants' understanding of TR and their role and the project's role in the clinical department at the hospital. In addition, questions were asked about the conditions, challenges, and opportunities related to conducting hospital-based research. I developed interview questions iteratively based on prior interviews, observational data, and the study of documents. Documents, such as research protocols and drafts, journal publications, ethics and funding applications, were analyzed to gain an understanding of the research projects and the work issues involved. A key informant also shared two years of email correspondence regarding the research project. Ethical approval and consent was obtained in writing from the principle investigators of the research networks and from informants.

Throughout the research project, I was simultaneously working as a consultant in a crosscutting research and innovation support unit at the hospitals. This involved weekly visits, meetings, workshops, and communication with staff and management at the hospital departments on issues related to research development and support in the region. This concurring consultancy work gave me a background understanding of the organization and the research infrastructure of the hospitals, but it is not included as a formalized part of the data set due to research ethics of a dual role of employee and researcher. This dual role in the field also positions my research as situated and intervening in the practices studied (Haraway, 1988; Zuiderent-Jerak, 2015).

The interview, transcripts, notes, and documents were analyzed using situational maps (Clarke, 2005) as an analytical tool for grasping and mapping out the research networks and the practices of clinician-scientists. Following situational analysis, I created three types of maps - situational maps, arena maps, and positional maps - iteratively to visualize and organize data. The maps also served as fruitful artefacts to allow for discussing ongoing analysis ideas with colleagues and informants. Data was stored, organized, and coded in the qualitative data analysis software NVivo. The coding frames were developed iteratively in NVivo, alongside the situational maps, and consisted firstly of descriptive, inductive codes and further on in the analysis process of analytical codes that were guided by a synthesis of the descriptive codes and the situational analysis maps.

\section{Analysis}

This section presents selected findings from the mapping and analysis of the arenas in which clinician-scientists engage in their daily work. Focus is on how clinician-scientists work within and meet demands of multiple arenas. Fourteen arenas were mapped in the study through iterative situational mapping, yet detailing the commitments of all these arenas however lies beyond the scope of this paper. Following Clarke (Clarke, 2005) the arenas could be analyzed in more detail into a number of sub-arenas depending on the scope and interest of the study.

The four arenas, designated as Hospital clinical, Hospital management, Cross-disciplinary collaboration and Patients are foregrounded in the present paper as they are empirical selections particularly specific to health care research and focus area of TR. The selection serves 
to exemplify that the research-clinic relationship materializes itself in multiple ways in the various arenas and how research and clinic play into one another in numerous and varying ways. All fourteen arenas are merely mentioned here to highlight the way in which clinician-scientists are engaged in a complex of multiple arenas. In a discussion of a preliminary arena mapping, a clinician-scientist pointed out; "all the arenas contribute to moving research forward and into the clinic". The way in which this multiplicity of commitments and capabilities is brought together by clinician-scientists is suggested to be constitutive of TR (Michael et al., 2007).

\section{Hospital clinical arena}

Firstly, I will present the analytically delinated hospital clinical arena with examples from the data material to illustrate how research in the clinic is formalized organizationally, established through material arrangements, but also continually a space of negotiation "under pressure". The clinician-scientists in the present study describe their clinical work as related to their formal written contract according to which they are allocated a certain percent of their time to patient consultations and other clinical tasks. The formal conditions of this contract are described below by a clinician-scientist recently employed in the oncology department as professor. The research related responsibilities of her employment consist of both building the research capacity at the department as well as further developing international research on the cancer treatment technique electroporation. This is combined with clinical duties at the oncology department and she identifies herself as both a clinician and a scientist, interested and deeply engaged in both the basic microbiological understanding of electroporation as well as in the manifestations of cancer and possible treatments in the clinic.

They have me on the schedule 2 days in the clinic. There, I have a set of tasks that are not necessarily related to what I know and can, but I add to production. That is the formal agreement with the university for most clinical professors and clinical associate professors. When a clinical department hires you, those are the terms, and then in turn they receive research support and development in the department. (interview, clinician-scientist, oncology)

To her, a hospital clinic arena can be outlined as a place of production where clinician-scientist and other staff members are committed to moving patients through somewhat standardized flows of diagnosis and treatment. This work, however, is not necessarily understood as connected to her more research specific competencies - "what I know and can". Also, as noted in the quote above, there is a transactional exchange. The clinical department buys into a given contract upon hiring a clinician-scientist, receiving a part time clinical production resource as well as research support and research based development of the clinic from within, since the clinician-scientists work alongside the clinical staff and become an integrated part of the clinical team.
Clinician-scientists and their managers stress that the clinic is a setting of work where time and finances are under pressure due to yearly cutbacks in the hospital and in departmental budgets. The concern of clinical departmental managers is making budget ends meet and achieving target production requirements for numbers of patients diagnosed and treated. Research is thus continually "squeezed out" and under pressure from the demand of clinical production. The oncology professor explains:

During my time as a doctor, clinical work has moved towards more and more requirements for what one has to do. Both the number of patients one has to see, but also all the other things one has to do, for example registration and documentation work in the clinic. A day of a doctor is just packed to the max now. So it is more difficult to find time to do other things such as research. (interview, clinician-scientist, oncology)

The clinical hospital environment was busy and often noted as a place where staff are just too few to carry out the necessary and required clinical tasks. In this setting, the work of securing research time for one's own research activities and for research related interactions with clinical staff required persistence and continuous effort.

A clinician-scientist in the children and youth psychiatric department, also a team leader of a clinical team, describes how the situation in her clinical team is fraught and fragile due to insufficient resources and a constant overbooking of patients. One clinician in her team has recently resigned, and another is on sick leave due to stress. She has, since the onset of her employment as a clinician-scientist, been engaged in an ongoing negotiation concerning how much clinical work she herself and the two Ph.D. students in her project can take on. She explains how this negotiation is a balancing act between securing protected research time for her own research tasks and for the research time of her Ph.D. students - and at the same time showing willingness to help alleviate the critical clinical situation of a lack of resources and overbooking of patients. During the entire period encompassed by the present study, negotiations were ongoing between this clinician-scientist and the department management concerning which kind of clinical tasks lie within or outside of her scope of work, as well as the work of her Ph.D. students.

Another clinician-scientist went to work in the department at seven in the morning to have time "before work starts at 8", before the first medical conference meeting. In these outer "timefor research-slots", the younger doctors in the department could drop by her office and ask questions, for example in relation to starting up research projects. Here, a space for research-related interactions with and among clinical staff was created.

In relation to getting the other staff members interested and involved in research, many of the clinician-scientists invested time and effort in establishing new meeting structures where research 


\section{$\$$}

NORDIC JOURNAL

of Science and Technology Studies

could be presented and shared, various seminars, and, for example, educational events that could "upgrade" staff members in relation to research - in part in order to fulfil the barter of research support and development in the department. However, convincing "nonresearch" staff (and management) to set time aside to participate in such activities was a continual challenge in this production setting maxed with clinical tasks and time pressure, and characterized by a very different flow of work tasks than that of discussing an article in a journal club meeting or jointly exploring preliminary research results.

At the same time, clinical work was highly valued and something most of the clinician-scientists referred to with pride and viewed as part of their professional profile. "Staying in touch with the patient in the clinic" was seen as crucial to ensuring relevance of their research work, and variations of "making a difference for the patient" was often mentioned as motivation for the career choice as clinician-scientist versus a university-based research career. A younger researcher embarking on a clinician-scientist career in psychiatry noted the following:

The research (carried out in a previous university position) is to a large extent isolated from clinical work, and when I came out and into the clinic and saw the discrepancies, well, that's why I applied for a clinical position, because the research I was working on is just not practically applicable. (interview, clinicianscientist, psychiatry)

Besides the accounts of personal motivation and making a difference for patients, having a good network and maintaining close collaborative relations among the staff in the clinic was also crucial. A "network in house" was necessary in order to have other staff members willing to assist in carrying out research activities or willing to help recruit and refer patients to a study protocol. In this way, the clinical arena and the work relations of the clinical department were conditional for conducting research projects, for the referral of patients to the study and for producing research results. Access to and recruitment of patients was somewhat competitive, as departments had many ongoing research projects, and patients were in high demand.

To summarize, the hospital clinical arena of the clinician-scientists can be characterized as a set of clinical/research border crossing and transactional practices. The role of research in the clinic was in part formalized in contracts and agreements, but also continually under negotiation. Pressures of production "squeezed" and challenged research activities and research-clinic relations. The practices constituting this arena thus entailed a creative and continuous negotiating of time and space for research, e.g. percentages in formal contracts, definition of relevant/irrelevant tasks, physical spaces and equipment, roles of assisting staff and new meeting structures. Likewise, building and maintaining the relations among staff members in the clinic was necessary in order to carry out hospital-based research projects.

\section{Hospital management arena}

The second analysis section presents an arena where research is positioned, on the one hand, as a solution, and on the other hand, as a disturbance. Focus is on how the clinician-scientists navigate this tension. Hospital management concerns formed part of the clinician-scientists' orientation in formulating research issues and in thinking about how research findings might find relevance in the clinical work setting. For example, the clinician-scientists incorporated managerial concerns as part of the research problem formulation. In a presentation for the hospital management, part of the application process for funding as a prioritized hospital "elite consortium", two clinician-scientists working together across specialties of surgery and oncology refer directly to departmental budgets at the opening and closing of their research pitch and presentation:

The budget for medicine at the Oncology Department is only going up and up. How can we avoid the large rate of relapses? What can we do to ensure that these patients are not referred on to oncology? How can we avoid that they become oncological patients? The presentation moves on to show how the research with its new treatment modalities aims to prevent cancer relapse. The presentation likewise closes with the statement: We are going to see this in the clinic. We are going to see the effects on the bottom line. (meeting notes, meeting where potential cross departmental "elite consortiums" presented research proposals)

Here, in their presentations, the clinician-scientists are speaking directly to the acute management agendas of rocketing medicine expenses and the departmental budget crisis. The clinicianscientists stipulate that if the project leads to lower recurrence rates, the budget implications could be great because treatment for extensive cancer is very expensive. Here, in the planning of a new research project, research is translated into a possible solution to a hospital management dilemma.

A clinician-scientist in the psychiatric department expresses another type of concern in relation to his department management and fellow clinical colleagues - concerns that the research project they have underway might be used as a tool for further cutbacks and reductions in consultation time between clinician and patient.

Our research could really take part in saving resources here at the clinic. However, this could also be unpopular, really. Imagine that we presented a set of tests that made it possible to cut down on clinical time with the patient. The clinicians already feel so pressured, and our research could become a tool for management, so to say, instead of a knowledge tool. (interview, clinician-scientist, psychiatry) 


\section{$\$$}

NORDIC JOURNAL

of Science and Technology Studies

The clinician-scientists expressed a concern that the research results could be used to alleviate or cut back on staff, possibly leading to less consultation time with the psychiatric patients, but perhaps also freeing up time for research and development. The quote above points to the inherent uncertainty regarding for whom and for what purposes new research knowledge is related to the department and the various ways in which it becomes part of clinical practices and possible agendas of optimization. Navigating and tinkering with multiple interests and agendas of e.g. management and colleagues thus constituted a part of clinician-scientists' work practices.

Another theme mapped as part of the hospital managerial arena was an "academization of the clinic". This theme cut across the political and strategic documents of the region and hospital. It was present as a topic in meetings as well as among the clinicianscientists' own reflections on their role in the clinical department. This is, in part, concerned with making the clinic more "evidencebased", about improving the competencies of the clinical staff and the overall quality of care by implementing the newest research knowledge and evidence in the clinic (Moreira, 2007; Timmermans and Berg, 2003).

We have these people with surplus energy that come in and are both clinically and research-wise super talented, they have a network-based and positive approach to what is possible and what isn't. And they are quick to pinpoint, when something is tradition or habit, this is what we have always done. But what is the data and evidence here? And where do we need more research? So really, it changes the culture. (interview, department manager, oncology)

Hospital managers and staff also referred to a fruitful "academic stimulation of the clinic and the clinicians not working directly with research". For example, discussions recurred on how research can lift the qualifications of the entire clinical staff - create "curiosity" or "humbleness" with regard to evidence.

With research you create a curiosity among colleagues that might not have been there before. This might influence how you diagnose a patient, maybe research can spark a curiosity so I have to check out how they do it in England or something like that... I suppose the research environment creates a general humbleness with regard to evidence. You learn to interpret data and interpret publications - so you learn about the issues involved in creating good evidence for clinical practice. (interview, research engineer, medical imaging)

Here, creating an understanding among the staff about how evidence is created and about different kinds of evidence, promotes a work environment of curiosity and questioning, consequently improving quality of care in the light of newest evidence. Having the clinician-scientists in the clinic alongside the other staff members in the oncology department was highlighted as the way in which the clinician-scientists and other staff members meet each other, where they have interactions, where they get to know each other. One clinician-scientist gives an example of young doctors, who, without the clinician-scientists, would have continued their medical training, but instead were encouraged to pursue a research idea.

That happens because we now have people (clinician-scientists) who stimulate their ideas... and then the ball starts rolling because these young people have also been in the clinic before they started researching, they have a good network, and now they have gotten involved in doing the morning educational sessions for their colleagues, ensuring further education because they want to give something back. It is a positive spiral, what I see happening. (interview, clinician-scientist, oncology)

So here, a reinforcing ripple effect is eluded, that research orientations and interest has spread and grown in the department through the presence and activities of the clinician-scientists employed there. Research was also brought forward as linked to professional pride and a motivational work factor for the entire staff. In a situation of high work pressure, research was noted as something that could "keep the higher goal in mind" and "make us want to be among the best".

Another way research was discussed as a way of optimizing the clinic is the way in which research could improve recruitment of personnel to the department. Research was, for example, often mobilized as an effective tool in the competition for qualified staff. It was somewhat difficult for the hospitals of Region Zealand to recruit for clinical positions and an issue of general concern. At departmental meetings, the recruitment of clinical staff was discussed in various situations. The possibility of new staff getting involved in research projects was highlighted as an important parameter for recruiting young, qualified clinical staff. It was noted by a department manager in the children's psychiatry department that people involved in research projects might stay on in the clinic after a project ends.

Their employment (a clinician-scientist) lends recognition to this department, so when you as a young doctor are applying, it is one of those things that says ok, this is a good place to be. It is getting easier for us to recruit younger doctors. (interview, department manager, psychiatry)

Research was thus in various ways posed as the key, a solution to some of the current challenges of the hospital; increasing productivity, keeping the clinic up-to-date with the newest evidence and best practice, keeping staff motivated and engaged, recruiting talented staff. The clinician-scientists position themselves in relation to these opportunities and possibilities. They thereby constitute an arena, where management concerns are relevant and a necessary part of their professional repertoire and where research in a number of ways can improve and develop the department. At the 
same time, in other situations, research constituted a potential disturbance, interfering with the planned flow of patients through a set of standardized diagnosis and treatment modalities. One clinician-scientist explains how the research aims of the project clash with a political managerial agenda in which cancer treatment must adhere to a certain limited time frame. Anything that can prolong the time of cancer treatment, such as an additional experimental treatment intervention, must be negotiated in relation to short and definite diagnosis and treatment time limits that a department must live up to. It was thus necessary for the clinician-scientists to continually communicate the relevance and importance of a research project - sometimes in a setting of little mutual interest from overworked colleagues or in a setting of many research projects and the associated clinician-scientists "competing" to recruit the same patients to their study.

\section{Cross-disciplinary collaboration arena}

This third analysis section depicts how clinician-scientists simultaneously deploy their work across various disciplines and medical specialities. The TR projects studied here are at the outset and by definition transdisciplinary, involving collaboration within the region, nationally within Denmark, as well as internationally. The autism research network, for example, spanned different departments and disciplinary specializations of child and youth psychiatry, psychology, psychophysiology, radiology, neurology, engineering, and screening software/IT development. The cancer project likewise cut across a number of medical/research specializations; oncology, surgery, dermatology, pathology, biochemistry, molecular biology, immunology, physics, engineering, IT, and palliation. Thus, a complex of specialized knowledges and practices were joined together.

Hospitals in Denmark, as abroad, are primarily organized in departments and medical specializations. The clinician-scientists explained how different styles or cultures of research exist among these departments, and elsewhere the historical separation, or "narrowing"' and the hierarchy of medical specializations has been discussed (Hindhede and Larsen, 2018; Nancarrow and Borthwick, 2005). In the networks studied here, the clinician-scientists were continually attempting to connect and integrate these different disciplines and the different investigational procedures and techniques. When explaining the translational design of the research projects, the informants from both research networks had different ways of referring to a "bigger picture", "holism", "a helicopter perspective", or "pieces in a puzzle" - when discussing their way of working across disciplines and techniques.

In one interview, a clinician-scientist from the psychiatry project draws the research design spanning different "translational levels" on the white board. She explains the methods and TR design of the project discussed, the different procedures and examinations the patients and control subjects go through, ranging from clinical screening and tests and electroencephalography (EEG) to magnetic resonance imaging (MRI). These methods provide knowledge on different translational levels from the "psychosocial down to something more and more biologically based". A version of this model was also refined for the project description and funding applications as a way of illustrating the different knowledge types that the project aims to connect and translate between.

A lot of the research that is carried out today is just not informed by complexity-based theories about how things are connected.... So you have to create new knowledge that involves connecting all of these levels (points to translational model on the board) (interview, clinician-scientist, children's psychiatry)

In the cancer project, a similar aim was explained as part of the TR design by a clinician scientist from the surgical department.

It is about designing the study so you see the bigger picture and get at 360 degree view... If you want to make a difference and do research that moves the way we think, then you have to include all the parts and include the whole spectrum. (interview, clinician-scientist, surgery)

Here, for example, results from patient-reported outcomes, molecular biological examinations of blood samples, and immunological investigations of tumour material are linked up in the research project - as are different stages of cancer and phases of cancer treatment, for example pre, during, and post operation. Thereby encompassing the "whole spectrum" by working across and joining together differing techniques and niches of research.

This required collaborative and transactional capabilities in order to work across medical specializations and departments as well as internationally. For example, for the EEG in the autism project or the immunological analysis of tumors, expertise and equipment involved collaboration and partnerships with researchers and companies abroad. Finding the right partners and mentors, at earlier stages, was highlighted as crucial to establishing a TR project, and linking up to the right laboratories and expertise to enable for example Ph.D. students to be co-supervised and exchanged was also important. Arranging joint seminars and establishing or contributing to international working groups were all part of the ongoing work of the clinician-scientists framed here as involving a cross-disciplinary arena. A lot of time and effort was put into such networking activities as seminars and conferences, meetings, and workshops in order to share and align research concerns. Shared work objects included research protocols, collaboration agreements, contracts, funding applications, journal articles, data and analysis materials, access to/sharing equipment, and joint supervision of Ph.D. students - and the translational models and visualisations explained above worked to tie these projects together as coordinating work objects.

Clinician-scientists were either skilled in or learning to navigate in this cross-disciplinarity - both by creating research designs that connect different disciplinary contributions as well as in analyses 


\section{N}

NORDIC JOURNAL

of Science and Technology Studies

that bring different types of techniques and results together. So here, the realization of TR is not only concerned with establishing the integrations or pathways between clinic and research, but very much also about creating dynamic collaborations across disciplines and techniques. This work of building and maintaining relations, developing one's understanding of or communication across specializations, and across other clinical-research networks was an ongoing and continuous part of the clinician-scientists' work practices.

\section{Patients' arena}

"The patient is everything" is the motto of the university hospital, in line with political streams of more patient-centred care regimes in Denmark and internationally (Smith et al., 2019). In conversations and interviews, most of the clinician-scientists also place patients at the core of their work. The health of their patients was in various ways framed by all of the clinician-scientists as "the ultimate target" of their work, thus resonating a therapeutic promise embedded in their research aims (Pickersgill, 2011). At the same time, patient data and patient materials also constituted their material work objects to be collected and analyzed. Tumor tissue, normal tissue, blood, medical images, tests results, and recorded experiences etc. comprised the substance of the research projects without which the research aims and this ultimate target could not be fulfilled. As noted earlier, a major issue was having enough patients enrolled in the individual research study. In various ways, the clinicianscientists paved the way for recruitment by involving internal staff members and perhaps looking to other departments for patients to include in their study. They also continuously monitor the number of patients acquired by means of different tools.
The presentation of a research project to the patient and family and their preparation for inclusion in a research project was also brought forward as a skill in itself. A Ph.D. student responsible for a related research protocol explains how she always has a patient consultation the day before the operation to talk about what the operation entails. Also, she is there alongside the patient throughout and after the operation and prefers to take the blood samples for the trial herself. She stresses that this is important "so the patient does not feel insecure about being part of an experimental trial." Here, the relations to and around patients were cared for in order to ensure patients and patient data for research purposes.

Likewise, efforts also went into preparing patients for "inclusion" in a study in order to keep them throughout the entire research flow of patient examinations. One of the research projects involved five very different types of examinations and tests of children diagnosed with autism, and here, in particular, the MRI brain scan and EGG testing was considered a challenge. Clinician-scientists referred to "pedagogical skills" of preparing the children and their parents for the examinations, explaining what they could expect, an open house Sunday where the children could visit and see the equipment beforehand, and extra EEG caps that the families could take home to play with etc.

As such, the patients' arena was constituted by yet another set of transactional orientations and capabilities that the clinicianscientists used to organize their work practices. This arena constitutes TR alongside the previously analysed arenas of hospital clinical, hospital management, and cross-disciplinary collaboration.

\section{Discussion}

The empirical analysis presented here sheds light on a complex of practices and situations where research and clinic play together and into one another. The multifaceted character of the clinicianscientist's work is unfolded in the account along with the ability of clinician-scientists to navigate this complex of multiple arenas, to meet many varying demands and to deal with the dilemmas and tensions involved. The paper depicts selected arenas of hospital clinical, hospital management, cross-disciplinary collaboration, and patients through examples and excerpts from the data. I have analytically delineated other arenas such as ethics, funding industry as part of the study, but a detailed presentation of all the arenas mapped are beyond the scope of the present paper. Following situational analysis, these arenas were mapped visually and thus provided a spatial view of the practices that contribute to moving research forward and to making it relevant. I found that these visual mappings served as very fruitful artefacts for sharing and discussing the findings with informants and other stakeholders in the region studied.

Further analysis could provide more detail on how the arenas overlap and intersect. For example, the patients arena is categorized here as a separate arena distinct from hospital clinical, although clinical work, of course, involves interactions and commitments to patients. The analysis is thus the result of the analytical mapping technique and aim of opening up and detailing the multiple character of the clinic-research relationship. Also, the study includes two quite different research networks within oncology and psychiatry. Further analysis could explore the different patterns of practice within different the specializations and the specific areas of research in question - for example also how these practices form part of broader biomedical collectives (Bourret, 2005; Keating and Cambrosio, 2012).

For now, this paper adds to existing STS literature and to efforts of opening the black box of TR from an empirically informed hospitalbased viewpoint. Where previous STS studies in this area have focussed on laboratory, materiality, ethics, and regulation, I have applied situational analysis as of one delimited setting in which hospital-based clinician scientists carry out TR work and presented a selection of these multiple work domains. Working with and 
bringing together multiple arenas is an aspect of work as a clinician scientist engaged in TR that tends to be overlooked in a dualistic understanding of TR as the bridging of two separate domains - clinic and research - or in the understanding of the clinicianscientist as a translator between the two. This prevalent policy conceptualization may render other aspects of a research-practice relationship less visible as well as obscure the multiple ways in which a research-clinic relationship can play out in the organizational hospital setting. The analysis presented in this article also turns our attention towards the relations, interactions, and exchanges that seem to move research forward while also making it relevant. In this sense, TR might be reframed transactional research in order to better address these collaborative relations and transactions. In the TR debate the concept of translation continually revokes the image of two worlds or logics to be transversed and translated between - clinic and research. Based on the study, it seems this the social and material work practices of TR more adequately might be characterized as a set of assembling and transactional practices across multiple (not only dual) arenas. The concept of transaction can help foreground this subtle aspect of clinician-scientists' work that seems difficult to grasp with existing dominant tropes and characterizations of translational research - e.g. bench-to-bedside, boundary work across worlds and logics.

Another interesting path for further inquiry is the very definition of translational research (Rushforth, 2016) and the very definition of clinician-scientists, how this professional position differs formally and practically in different countries, different political contexts, and historically. In Denmark the political demand for translational research is currently explicit in regional and national policy and is supported by various present public and privately funded initiatives such as educational programs and dedicated research programs. This resonates policy related discussions on translational and applied science internationally, involving for example initiatives for how the crucial role of clinician-scientists can be better supported through education, how the training of clinician-scientists can and should be improved, and how to provide career incentives as well as better infrastructure support ( McKinney, 2017). A recent research report in the journal Academic Medicine, opens with the statement "Physician-scientists - academic physicians who devote a substantial proportion of their time to conducting research - are a population in decline globally" (Lingard et al., 2017), and as mentioned, policies in e.g. USA, UK and Germany also aim to alleviate this apparent deficiency.
A contribution from an STS perspective to this policy debate could be to explore the ways in which organizations and policy and can recognize and make visible the transactional practices that make up an important part of the work of clinician-scientists. These subtle commitments and capabilities, as exemplified in this paper, are difficult to delineate and measure in the form of, for example, performance indicators. Current indicators tend to apply to academia on the one hand and clinical work on the other and cannot account for the ongoing complex of practices illustrated in this paper. The transactional work of clinician-scientists seems difficult to make visible and accountable short term with the frameworks available (Rushforth et al., 2016). Also, it seems that adding more performance demands, more obligations and expectations for this groups of actors to live up to, might not be fruitful in a situation where clinician-scientists already are strung out by multiple arenas. In fact, more performance demands might actually impede the productive transactional practices of building and sustaining relations, negotiating exchanges, and continually dealing with unforeseen tensions and difficulties that arise in such processes. How policy can account for, evaluate, and support this type of transactional work thus calls for further research. And here STS approaches and theoretical sensibilities of, for example, situational analysis, actornetwork theory, and practice theory are highly relevant.

On a more critical note, further STS informed research on TR might also focus on how translational/transactional work of clinician-scientists, and the political support for this work, is entangled with broader changes in biomedical research politics and shifting hierarchies of expertise. As touched upon in this paper, the clinician-scientists' profession is simultaneously presented in the TR literature as an uncertain and daunting career, and at the same time, this role is positioned as key leaders of change holding a privileged professional status in relation to the TR high hopes and visions (Vignola-Gagne, 2014; Wilson-Kovacs and Hauskeller, 2012). In this way, the work of clinician-scientists is located in a shifting professional landscape where authority and political prioritization currently is contested for different kinds of research and different kinds of researchers. This broader political landscape constitutes the backdrop and works as legitimizing for the local work practices discussed in this paper. Wilson-Kovacs and Hauskeller (2012) and Vignola-Gagne (2014) have focussed on TR's political and professional shifts and tensions in UK, USA, and Germany and their work likewise calls for similar questioning of Nordic TR visions and professional reconfigurations in the Nordic countries.

\section{Conclusion}

This research paper has reported from an empirical study of the practices of hospital medical staff in Denmark who hold combined positions as clinician-scientists in which they are expected to do both research and clinical work. In the paper I have shared selections from an in-depth analysis and situational mapping of the daily practices of these actors, who are framed in the field as "clinician-scientists". The paper outlines the work of these clinician-scientists as a case of translational research and as a set of practices and commitments that take place at the interface of academia and clinical health care. The paper thereby aims to increase our understanding of the local and specific doing of translation research in a current situation in 
which both the societal and the hospital sector demands forand funding for-applied and translational research is growing. The paper documents selected aspects of the everyday work of clinician-scientists, in particular how their work constitutes, and is constituted by, multiple arenas and a complexity of commitments and capabilities. The findings of the exploratory study presented in this paper thereby show the ability of the clinician-scientists to continuously perform in these multiple arenas and to live up to the multiple demands and capabilities required. I suggest that this multiple-transactional-performance and the situations in which research and clinic play into one another and together in different ways constitutes TR. This view of the practices of clinicianscientists adds to present understandings of TR in a hospital work setting. Rather than an image of the clinician-scientist as an actor with a foot in two worlds, as is prevalent in the TR literature and, in part, in STS literature (i.e. focus on boundary work), the analysis sheds light on multiple domains that are integrated, translated, and continually negotiated by clinician-scientists in order to move their own careers and hospital-based translational research forward. In conclusion, the paper suggests a reframing of translational research as transactional research in order to foreground the relations, interactions, and exchanges that seem to characterize the work of clinician-scientists. This reframing could be elaborated in further work to support these practices, thus informing and supporting the political TR agenda, or it could be used more critically to shed light on shifting hierarchies of knowledge and expertise, thereby questioning the very premises of the current societal and political demand for TR.

\section{Acknowledgements}

This research was funded by Data and Development Support, Region Zealand, and hosted by Department of People and Technology, Roskilde University. The study was carried out with support and supervision from Jesper Grarup, Peter Kjær, and the two research groups Health Promotion Research and Dialogical Communication at Roskilde University. Thanks also to Brit Ross Winthereik for suggesting the notion of transactional research and to thorough NJSTS reviewers.

\section{References}

Bourret, P., 2005. BRCA Patients and Clinical Collectives. Social Studies of Science 35, 41-68.

Brosnan, C., Cribb, A., Wainwright, S.P., Williams, C., 2013. Neuroscientists' everyday experiences of ethics: the interplay of regulatory, professional, personal and tangible ethical spheres. Sociology of Health \& IIIness 35, 1133-1148.

Brosnan, C., Michael, M., 2014. Enacting the 'neuro' in practice: Translational research, adhesion and the promise of porosity. Social Studies of Science 44, 680-700.

Clarke, A.E., 2005. Situational analysis: grounded theory after the postmodern turn. Sage Publications.

Crabu, S., 2018. Rethinking biomedicine in the age of translational research: Organisational, professional, and epistemic encounters. Sociology Compass 12 (10), e12623.

Douglas, C., Lander, B., Fairley, C., Atkinson-Grosjean, J., 2015. The Roles of User/Producer Hybrids in the Production of Translational Science. Social Epistemology 29, 323-343.

Dunn, M.B., Jones, C., 2010. Institutional Logics and Institutional Pluralism: The Contestation of Care and Science Logics in Medical Education, 1967-2005. Administrative Science Quarterly 55, 114-149.

Foucault, M., 1990. The history of sexuality. Volume 1, an introduction. Vintage.

Fudge, N., Sadler, E., Fisher, H.R., Maher, J., Wolfe, C.D.A., McKevitt, C., 2016. Optimising Translational Research Opportunities: A Systematic Review and Narrative Synthesis of Basic and Clinician Scientists' Perspectives of Factors Which Enable or Hinder
Translational Research. PLOS ONE 11, e0160475.

Greenhalgh, T., Wieringa, S., 2011. Is it time to drop the 'knowledge translation' metaphor? A critical literature review. Journal of the Royal Society of Medicine 104, 501-509.

Haraway, D., 1988. Situated Knowledges: The Science Question in Feminism and the Privilege of Partial Perspective. Feminist Studies 14 (3) 575-599.

Hendriks, B., Simons, A., Reinhart, M., 2019. What are Clinician Scientists Expected to do? The Undefined Space for Professionalizable Work in Translational Biomedicine. Minerva 57(3), 1-19.

Hindhede, A.L., Larsen, K., 2019. Prestige hierarchies of diseases and specialities in a field perspective. Social Theory \& Health $17(2)$, $213-230$

Keating, P., Cambrosio, A., 2012. Cancer on trial : oncology as a new style of practice. University of Chicago Press.

Lander, B., 2016. Boundary-spanning in academic healthcare organisations. Research Policy 45, 1524-1533.

Law, J., 2017. STS as Method. In U. Felt, R. Fouché, C. Miller, L. SmithDoerr, The Handbook of Science and Technology Studies, 31-58. MIT Press.

Lingard, L., Zhang, P., Strong, M., Steele, M., Yoo, J., Lewis, J., 2017. Strategies for Supporting Physician-Scientists in Faculty Roles. Academic Medicine 92, 1421-1428.

Löwy, I., 1996. Between bench and bedside: science, healing, and interleukin-2 in a cancer ward. Harvard University Press.

Malterud, K., 2001. The art and science of clinical knowledge: evidence beyond measures and numbers. The Lancet 358, 397-400. 
McKinney, R.E., 2017. The Daunting Career of the PhysicianInvestigator. Academic Medicine 92, 1368-1370.

Michael, M., Wainwright, S.P., Williams, C., 2007. Temporality and Prudence: On Stem Cells as Phronesic Things; Configurations 13 373-394.

Miller, F.A., French, M., 2016. Organizing the entrepreneurial hospital: Hybridizing the logics of healthcare and innovation. Research Policy 45, 1534-1544.

Moreira, T., 2007. Entangled evidence: knowledge making in systematic reviews in healthcare. Sociology of Health \& IIIness 29, 180-197.

Moreira, T., May, C., Bond, J., 2009. Regulatory Objectivity in Action. Social Studies of Science 39, 665-690.

Nancarrow, S.A., Borthwick, A.M., 2005. Dynamic professional boundaries in the healthcare workforce. Sociology of Health and Illness 27, 897-919.

Pickersgill, M., 2011. 'Promising' therapies: neuroscience, clinical practice, and the treatment of psychopathy. Sociology of Health \& Illness 33, 448-464.

Rabeharisoa, V., Bourret, P., 2009. Staging and Weighting Evidence in Biomedicine. Social Studies of Science 39, 691-715.

Region Zealand Operations Research and Innovation, 2017. Opsamlingsrapport for midtvejsevaluering af forskningspolitikken i Region Sjælland. Available at https://www.regionsjaelland. dk/Sundhed/forskning/organisationogpolitik/Documents/ Midtvejsevaluering\%20rapport\%20web.pdf

Rushforth, A., 2016. What's in a slogan? Translational science and the rhetorical work of cancer researchers in a UK university. Nordic Journal of Science and Technology Studies 4(1), 32-42.

Rushforth, A.D., de Rijcke, S., 2016. Quality monitoring in transition:
The challenge of evaluating translational research programs in academic biomedicine. Science and Public Policy 34, scwo78.

Smith, E., Bélisle-Pipon, J.-C., Resnik, D., 2019. Patients as Research Partners; How to Value their Perceptions, Contribution and Labor? Citizen Science: Theory and Practice 4(1), 1-13.

Strauss, A.L., 1993. Continual permutations of action. Aldine de Gruyter, Swan, J., Goussevskaia, A., Newell, S., Robertson, M., Bresnen, M., Obembe, A., 2007. Modes of organizing biomedical innovation in the UK and US and the role of integrative and relational capabilities. Research Policy 36, 529-547.

Timmermans, S., Berg, M., 2003. The gold standard: the challenge of evidence-based medicine and standardization in health care. Temple University Press.

van der Laan, A.L., Boenink, M., 2015. Beyond bench and bedside: disentangling the concept of translational research. Health care analysis : HCA : journal of health philosophy and policy 23, 32-49.

Vignola-Gagne, E., 2014. Argumentative practices in science, technology and innovation policy: The case of clinician-scientists and translational research. Science and Public Policy 41 (1), 94-106

Wainwright, S., Williams, C., 2009. Stem cells, translational research and the sociology of science. In P. Atkinson, P. Glasner, M. Lock, Handbook of Genetics and Society: Mapping the New Genomic Era. 41-58. Routledge.

Wilson-Kovacs, D.M., Hauskeller, C., 2012. The clinician-scientist: professional dynamics in clinical stem cell research. Sociology of Health \& Illness 34, 497-512.

Woolf, S.H., 2008. The meaning of translational research and why it matters. JAMA 299, 211-3.

Zuiderent-Jerak, T., 2015. Situated intervention: sociological experiments in health care. The MIT Press. 